\title{
The Status Quo and Legal Regulation of Surrogacy in China
}

\author{
Chen Silin \\ School of Humanities and Law \\ Northeastern University of China \\ Shenyang, China
}

\author{
Yao Tianchong \\ School of Humanities and Law \\ Northeastern University of China \\ Shenyang, China
}

\begin{abstract}
Nowadays, how to solve the problem of surrogacy has become a major problem in Chinese society. China has problems with surrogacy on the issue of surrogacy and unclear judgments. It was intended to understand the status quo of the international "surrogate" legislation, and made recommendations for the formulation of relatively complete legal regulations to resolve the social contradictions of surrogacy. Found out the status quo of China's legislation and relevant jurisprudence by looking up the data, and compared the relevant regulations of other countries. It also proposes a legislative plan for gradually liberalizing surrogacy in China and applying various regulations to legalize it.
\end{abstract}

Keywords-Surrogacy; Legislative status; Legalization; Legal regulation; International regulations

\section{CONCEPT AND CLASSIFICATION OF SURROGACY}

\section{A. Concept of Surrogacy}

Surrogacy is a kind of assisted reproductive means, which refers to the combination of sperm and egg in vitro, and then implants the fertilized egg into the surrogate mother, and the birth process is completed by the surrogate mother.

\section{B. Two Types of Surrogacy in the Perspective of Comparative Law}

The subject, content, form and applicable conditions of the surrogacy contract may vary widely and should not be generalized. To further understand the concept of surrogacy, it needs to be classified specifically. The author advocates the following two classifications.

\section{1) Local Surrogacy and Complete Surrogacy}

According to whether there is a blood relationship between the surrogate mother and the fetus, surrogacy can be divided into local surrogacy and complete surrogacy. Local surrogacy is a fetus that combines the egg of the surrogate mother with the covenant's sperm through natural or artificial fertilization, and has a blood relationship with the surrogate mother. Complete surrogacy is to combine the sperm of the pregnant parents to form a fertilized egg implanted into the surrogate mother to form a fetus, the fetus and the surrogate mother have no blood relationship.

\section{2) Altruism and Commercial Surrogacy}

According to whether the compensation for the surrogate mother is within a reasonable range, surrogacy can be divided into altruism and commercial surrogacy. The so-called compensation within a reasonable range includes only the pregnancy and the related expenses incurred during childbirth, mainly refers to the medical expenses, living expenses and communication fees with the pregnant parents during pregnancy and childbirth, and does not include the payment of the surrogacy act itself.

\section{THE STATUS QUO OF SURROGACY LEGISLATION IN CHINA}

\section{A. China's current surrogacy laws}

Chinese law has a negative attitude towards surrogacy. The most direct norm is the "Administrative Measures for Human Assisted Reproductive Technology" issued by the Ministry of Health in 2001. Article 3 of the Measures stipulates: "It is forbidden to buy or sell gametes, zygotes and embryos in any form. Medical institutions and medical personnel shall not implement any form of surrogacy technology." In violation of this provision, in accordance with Article 22 of the Measures, "by The health administrative departments of the people's governments of provinces, autonomous regions and municipalities directly under the Central Government shall give warnings and impose fines of up to 30,000 yuan and give administrative punishments to the responsible persons; if they constitute a crime, they shall be investigated for criminal responsibility according to law. The attitude of the Ministry of Health in 2003, "Human Assisted Reproductive Technology and Ethical Principles of Human Sperm Bank" was reiterated.1

In addition, there is no clear regulation on surrogacy in our laws. In actual judicial judgments, what may be used in the various departmental laws may be related to surrogacy:

Article 7 of the General Principles of the Civil Law of the People's Republic of China states: "Civil activities shall respect social morality, shall not harm the public interest of the society, and disrupt the social and economic order." Article 7 of the Contract Law of the People's Republic of China states: "The parties conclude and perform the contract. It shall abide by laws and administrative regulations, respect social morality, and shall not disturb the social and economic order and harm the public interest." Article 52 stipulates that contracts that violate the mandatory provisions of laws and administrative regulations are invalid. And Article 25 of the Marriage Law of the People's Republic of China states: "Children born out of 
wedlock have the same rights as children born in wedlock, and no one may harm or discriminate. The father or mother who does not directly raise children born out of wedlock shall bear the children's Living expenses and education fees until the children can live independently."

\section{B. Relevantjudicial precedents in mainland China}

TABLE I. EXAMPLES OF SURROGACY CASES IN VARIOUS COURT S IN CHINA IN RECENT YEARS

\begin{tabular}{|c|c|c|c|c|}
\hline Court & Time & $\begin{array}{c}\text { Surrogate } \\
\text { Type }\end{array}$ & Judge & Refee \\
\hline $\begin{array}{c}\text { People's } \\
\text { Court of } \\
\text { Siming } \\
\text { District, } \\
\text { Xiamen City, } \\
\text { Fujian } \\
\text { Province }\end{array}$ & 2012 & Genotype & $\begin{array}{c}\text { The } \\
\text { custody is } \\
\text { pregnant } \\
\text { mother, } \\
\text { and the } \\
\text { father pays } \\
\text { for } \\
\text { support. }\end{array}$ & $\begin{array}{c}\text { The } \\
\text { surrogacy } \\
\text { agreement } \\
\text { violates the } \\
\text { public } \\
\text { order }\end{array}$ \\
\hline $\begin{array}{l}\text { People's } \\
\text { Court of } \\
\text { Dingcheng } \\
\text { District, } \\
\text { Changde } \\
\text { City, Hunan } \\
\text { Province }\end{array}$ & 2012 & Pregnancy & $\begin{array}{l}\text { custody } \\
\text { returned to } \\
\text { the father, } \\
\text { and the } \\
\text { surrogate } \\
\text { mother's } \\
\text { claim for } \\
\text { compensat } \\
\text { ion cannot } \\
\text { be } \\
\text { supported }\end{array}$ & $\begin{array}{l}\text { The } \\
\text { surrogate } \\
\text { mother is } \\
\text { not the } \\
\text { biological } \\
\text { mother of } \\
\text { the child }\end{array}$ \\
\hline $\begin{array}{l}\text { People's } \\
\text { Court of } \\
\text { Shunde } \\
\text { District, } \\
\text { Foshan City, } \\
\text { Guangdong } \\
\text { Province }\end{array}$ & 2010 & Genotype & $\begin{array}{l}\text { The } \\
\text { custody of } \\
\text { an } \\
\text { illegitimat } \\
\text { e child } \\
\text { belongs to } \\
\text { the father }\end{array}$ & $\begin{array}{c}\text { The } \\
\text { surrogacy } \\
\text { agreement } \\
\text { and the } \\
\text { abandonme } \\
\text { nt of the } \\
\text { custody } \\
\text { supplement } \\
\text { agreement } \\
\text { violate the } \\
\text { legal } \\
\text { provisions }\end{array}$ \\
\hline
\end{tabular}

In order to analyze the topic in depth, this paper selects several surrogate cases tried in courts in various places in recent years to observe the attitude of our country's justice to surrogacy. There are currently a limited number of surrogacy cases in China, but even so, we can find some valuable information and rules from a limited sample.

From Table 1, the courts in our country do not completely deal with surrogacy cases in accordance with the general principles of public order and goodness, but divide the surrogacy into two types: genotype and pregnancy. The purpose of the referee is that the genotype surrogacy agreement violates the public order and is a consensus of many courts. However, for the pregnancy-type surrogacy agreement, individual courts have given more tolerance and believe that it does not violate social morality and is an effective legal act.

However, since there is no clear provision in the law for "surrogate", the applicable law in judicial judgment can only invoke the provisions or legal principles of other departmental laws. Such a judge seems to be a bit blunt, the judge's discretion is too large, and there is a big controversy that cannot convince the parties. Therefore, it is extremely urgent to make clear legal provisions for "surrogate", which is of great significance to the judicial improvement of our country.

\section{DIFFERENT LEGISLATIVE ATTITUDES TOWARDS SURROGACY IN DIFFERENT COUNTRIES}

The attitudes of current national legislation on surrogacy can be divided into two types, namely, rejection and acceptance, and to a certain extent, the trend of surrogate is gradually released. A refusal attitude is usually a total ban on all forms of surrogacy. Accepting surrogacy often involves accepting a specific type of surrogate while applying multiple restrictions.

\section{A. Completely negating surrogacy Abbreviations and Acronyms}

Completely denying surrogacy means prohibiting all forms of surrogacy. For example, the current Civil Code of France stipulates that any pregnancy- or birth-related agreement by a third party is null and void. The Quebec Civil Code of Canada stipulates that any agreement by a woman to have a child for another is absolutely ineffective. It is not difficult to see through these legal provisions that the attitudes of these countries towards surrogacy are completely negated, and all surrogacy acts are prohibited by legislation.

\section{B. Partially accepted surrogate}

Partially accepted surrogacy can be divided into three different forms of expression: accepting altruistic surrogacy, accepting full surrogacy, and accepting altruistic full surrogacy.

\section{1) Accepting Altruistic Surrogacy}

Article 2, paragraph 1, of the British Surrogacy Agreement Act of 1985 stipulates that commercial surrogacy and intermediary activities cannot be carried out, and even information cannot be compiled to communicate or sign commercial surrogacy. In 1990, the Human Fertilization and Embryology Act supplemented the implementation measures of surrogacy and the effectiveness and parent-child relationship of surrogacy agreements, which made up for the shortcomings of the previous law, but did not stipulate the need to adopt a full surrogate method. Article 5 of the Supplementary Human Reproduction Act of Canada in 2004 explicitly prohibits the payment of remuneration to find surrogate mothers, while prohibiting intermediaries related to surrogacy, and not paying mediators. New Zealand's 2004 Artificial Assisted Reproductive Technology Act also prohibits all business activities related to surrogacy, but allows for the payment of reasonable and necessary expenses for specific purposes, including: collection, storage, transportation and use of persons Gametes, counseling surrogate contract parties, fertilization and artificial assisted reproduction, ovulation and pregnancy testing, and legal counseling. This kind of legislation emphasizes the altruism of surrogacy and avoids the commercialization of surrogacy.

\section{2) Accept Full Surrogate}

South Africa's Law No. 38 of 2005, which was officially enacted on June 8, 2006, recognizes full surrogacy and requires that the gametes come from both parents, unless one party cannot provide gametes due to physiological or medical reasons, and single pregnancy the Party must provide its own 
gametes. This kind of legislation focuses on emphasizing the blood relationship between surrogate children and pregnant parents, avoiding the abandonment of surrogate children and focusing on the protection of surrogate children.

\section{3) Accept Altruism}

The states of Florida, Virginia, and New Hampshire only recognize full surrogacy contracts and stipulate that reasonable expenses for surrogacy include only reasonable living expenses directly related to pregnancy and childbirth, as well as legal, medical, psychological, and spiritual problems. Partially accepting surrogacy can not only prohibit other forms of surrogacy, but also effective legal regulation of surrogacy. On the one hand, it can provide a clear legal basis for resolving related disputes, on the other hand, it helps to form a standardized management system, which is more reasonable. Effectively regulate surrogacy behavior.

\section{THE LEGAL REGULATION OF SURROGACY}

Looking at the attitudes of other countries and regions on the act of surrogacy, the limited opening of surrogacy is the general trend. However, at the same time of opening up, it is necessary to combine the social development needs of China at this stage and the moral and ethical awareness of the people to impose necessary restrictions on them. We can get important enlightenment from the legislative practice of other countries. Therefore, the following legislative ideas are proposed.

\section{A. Surrogate Technology Should be Used as Medical Means}

The surrogate is applied to the wife's factor defect or other couples who are not suitable for pregnancy and cannot develop their own fetus. Surrogacy technology is a derivative of artificial assisted reproductive technology. Artificial assisted reproductive technology was originally created to solve the problem of infertility. To achieve the fit between surrogate technology and ethics, surrogacy technology should be limited to medical applications and should not be made into a general fertility model. "The greatest purpose of artificial reproductive technology is not to play the role of God, but to satisfy the infertile couples so that they can win children." Therefore, reproductive function is normal, in order to avoid the risk and suffering of childbirth or worry about fertility affecting their careers. Women can't seek surrogacy. Secondly, surrogacy is only open to legal couples. Gay marriage has not been accepted by universal social ethics in China, nor is it recognized by law. Single-parent families have uncertainty in the protection of children's interests, and the realization of reproductive rights of same-sex couples and singles The problem is still inconclusive, and surrogacy is not suitable for opening to such people.

\section{B. Allowing Reasonable Compensation for Surrogate Mothers}

It is the general idea in surrogate regulation in most countries that the surrogate mother cannot be overcompensated to avoid the corruption or breeding of evil caused by money and adversely affect the social atmosphere. However, there is no uniform standard for the determination of "reasonable scope". Through the above analysis of the scope of compensation for various states in the United States, the author believes that the scope of payment should include "the costs associated with surrogacy during the surrogate motherhood. For example, medical expenses for pregnancy and production, nutrition costs, loss of income during pregnancy production, etc., can also be given a certain amount of remuneration due to the burden and risk of pregnancy. Paying a certain amount of remuneration is conducive to the stability of the surrogacy relationship, and also to the interests of the surrogate mother and the entrusted husband and wife. Certain money or material giving is a common way for people to express gratitude. It does not of course cause social corruption, but it should not be too high to avoid the distortion of values caused by exaggerated money factors.

\section{Strictly restricting the subject of the surrogacy contract}

In order to prevent the abuse of surrogacy technology, the law should strictly limit the surrogacy subject. The Party to the surrogate contract should be the entrusted couple. The specific qualifications are as follows: First, the entrusted behavior needs to be voluntarily agreed and jointly entrusted by the couple; secondly, the entrusted couple have healthy germ cells, and do not need to accept sperm donation or donate eggs; third, the wife meets one of the following circumstances: (1) The wife has no uterus; (2) The wife has a pregnancy disorder in her uterus; (3) The wife is life-threatening or seriously affects her health due to pregnancy or childbirth; Fourth, she is assessed to be suitable for psychological and physiological conditions. Entrust the couple. The other party to the surrogacy contract should be the surrogate mother and his or her spouse (if married). The qualifications for surrogate mothers are as follows: first, surrogate mothers must have full capacity; second, surrogate mothers must be completely voluntary; third, surrogate mothers must be 20 years of age and have given birth; fourth, assessed surrogate the mother's physical and psychological conditions are suitable for surrogacy.

\section{CONCLUSION}

The double-sided nature of artificial birthing technology makes people unable to resolve their negative effects when they enjoy the happiness brought by surrogate technology. Before the system is established and perfected, it is forbidden to become the most helpless and safest choice. However, this practice has been increasingly questioned, and it is an inevitable trend to gradually release surrogacy. This trend is also an inevitable choice for modern society to treat new things to ensure the continuous advancement of society. However, while opening up, we need to regulate the legislation and legislative boundaries of this legislation, so that surrogacy will bring the greatest benefits to society and people.

\section{REFERENCES}

[1] Gao Shanshan, Study on the legal status of children born in surrogacy[J]. Legality Vision, 2018(03):171.(in Chinese)

[2] Liu Yanhua, Legal Regulation of Paid Surrogacy - A Perspective of Law and Economics[J]. Fujian Law, 2017(01):67-72. (in Chinese)

[3] Wang Liqing, On the legal regulation of limited surrogacy[J]. Chinese Health Service Management, 2014,31(09):687-690. (in Chinese)

[4] Zhang Geng, Study on the legalization of surrogacy in China[D].Yangzhou University, 2017(in Chinese) 